Supporting Information for

\title{
Nickel-Platinum Nanoparticles as Peroxidase Mimics with a Record High Catalytic Efficiency
}

Zheng Xi, ${ }^{\dagger}$ Kecheng Wei, ${ }^{\S}$ Qingxiao Wang, ${ }^{\mathfrak{f}}$ Moon J. Kim, ${ }^{£}$ Shouheng Sun, ${ }^{\S}$ Victor Fung, ${ }^{\ddagger},{ }^{\star}$ and Xiaohu Xia ${ }^{\dagger, l, *}$

${ }^{\dagger}$ Department of Chemistry and "Nanoscience Technology Center, University of Central Florida, Orlando, Florida 32816, United States

${ }^{\ddagger}$ Center for Nanophase Materials Sciences, Oak Ridge National Laboratory, Oak Ridge, Tennessee 37831, United States

${ }^{\S}$ Department of Chemistry, Brown University, Providence, Rhode Island 02912, United States

${ }^{\mathfrak{E} D e p a r t m e n t ~ o f ~ M a t e r i a l s ~ S c i e n c e ~ a n d ~ E n g i n e e r i n g, ~ U n i v e r s i t y ~ o f ~ T e x a s ~ a t ~ D a l l a s, ~ R i c h a r d s o n, ~}$ Texas 75080, United States

*Corresponding author. E-mails: Xiaohu.Xia@ucf.edu (X.X.) and fungv@ornl.gov (V.F.) 


\section{Experimental Section}

Chemicals and Materials. Tetraethylene glycol (Tetra-EG, 99\%), platinum(II) acetylacetonate ( $\left.\mathrm{Pt}(\mathrm{acac})_{2}, 97 \%\right)$, nickel(II) acetate tetrahydrate ( $\mathrm{Ni}(\mathrm{ac})_{2} \cdot 4 \mathrm{H}_{2} \mathrm{O}, 98 \%$ ), polyvinylpyrrolidone (PVP, MW $\approx 55,000$ ), acetaldehyde (99\%), 3,3',5,5'-tetramethylbenzidine (TMB, 99\%), hydrogen peroxide solution (30\%), acetic acid (HOAc, 99.7\%), sodium acetate (NaOAc, 99\%), carcinoembryonic antigen (CEA, 98\%), Tween 20, bovine serum albumin (BSA, 98\%), Nhydroxysulfosuccinimide sodium salt (NHS, 98\%), N-ethyl-N'-(3-(dimethylamino) propyl)carbodiimide hydrochloride (EDC, 99\%), sodium chloride ( $\mathrm{NaCl}, 99.5 \%$ ), potassium chloride $(\mathrm{KCl}, 99 \%)$, sodium carbonate $\left(\mathrm{Na}_{2} \mathrm{CO}_{3}, 99.5 \%\right)$, sodium bicarbonate $\left(\mathrm{NaHCO}_{3}, 99.7 \%\right)$, sodium phosphate dibasic $\left(\mathrm{Na}_{2} \mathrm{HPO}_{4}, 99 \%\right)$, potassium phosphate monobasic $\left(\mathrm{KH}_{2} \mathrm{PO}_{4}, 99 \%\right)$, sodium azide ( $\left.\mathrm{NaN}_{3}, 99.5 \%\right)$, citric acid (99\%), acetone (99.5\%), ethanol (99.5\%) and sulfuric acid $\left(\mathrm{H}_{2} \mathrm{SO}_{4}, 98 \%\right)$ were all purchased from Sigma-Aldrich. HS-PEG $3400-\mathrm{COOH}(\mathrm{MW} \approx 3,400)$ was purchased from Laysan Bio, Inc. Mouse anti-CEA monoclonal antibody (mouse anti-CEA mAb) and rabbit anti-CEA polyclonal antibody (rabbit anti-CEA pAb) were purchased from Abcam plc. Goat anti-mouse IgG and HRP-goat anti-mouse IgG conjugate were purchased from Thermo Fisher Scientific, Inc. Microtiter plates (96-well, polystryene, clear, flat bottom) were purchased from Corning Inc. All aqueous solutions were prepared using deionized (DI) water with a resistivity of $18.2 \mathrm{M} \Omega \cdot \mathrm{cm}$.

Instrumentations. UV-vis spectra were recorded using an Agilent Cary 60 UV-vis spectrophotometer. Transmission electron microscopy (TEM) images were taken using a JEOL 1011 microscope operated at $200 \mathrm{kV}$. High-angle annular dark-field scanning TEM (HAADFSTEM) images were taken using a FEI $200 \mathrm{kV}$ Titan Themis scanning transmission electron microscope. The concentrations of $\mathrm{Pt}$ and $\mathrm{Ni}$ ions were determined using inductively coupled plasma atomic emission spectroscopy (ICP-AES, JY2000 Ultrace ICP atomic emission spectrometer equipped with a JYAS 421 autosampler and $2400 \mathrm{~g} / \mathrm{mm}$ holographic grating), which could be converted to the particle concentration of Ni-Pt and Pt NPs once particle size had been resolved by TEM imaging. X-ray Diffraction (XRD) patterns were recorded using a PANalytical Empyrean diffractometer (1.8 KW Copper X-ray Tube). X-ray photoelectron spectroscopy (XPS) was performed on a Physical Electronics 5400 ESCA spectrometer system. Microtiter plates were shaken using a Corning LSE digital microplate shaker. The absorbance of samples in microtiter 
plates was read using a Biotek Synergy H1 Hybrid Multi-mode plate reader at absorbance $\lambda_{\max }=$ $450 \mathrm{~nm}$. $\mathrm{pH}$ values of buffer solutions were measured using an Oakton $\mathrm{pH} 700$ benchtop meter.

Synthesis of Ni-Pt NPs. In a standard synthesis of Ni-Pt NPs (samples in Figure 1 and S2), $10 \mathrm{mg}$ (0.025 mmol) Pt(acac) $2,7 \mathrm{mg}(0.025 \mathrm{mmol}) \mathrm{Ni}(\mathrm{ac})_{2} \cdot 4 \mathrm{H}_{2} \mathrm{O}, 80 \mathrm{mg}$ PVP and $10 \mathrm{~mL}$ tetra-EG were first mixed by magnetic stirring in a $100 \mathrm{~mL}$ four-neck flask and degassed under a gentle flow of $\mathrm{N}_{2}$ at $100{ }^{\circ} \mathrm{C}$ for $30 \mathrm{~min}$ to form a clear solution. Then under $\mathrm{N}_{2}$ blanket, $1 \mathrm{~mL}$ acetaldehyde/tetraEG mixture (1/1 volume ratio) was quickly injected into the solution. The solution was then heated to $280^{\circ} \mathrm{C}$ at $10^{\circ} \mathrm{C} / \mathrm{min}$ and kept at $280^{\circ} \mathrm{C}$ for $1 \mathrm{~h}$ before it was cooled to room temperature. After synthesis, the Ni-Pt NPs as products were precipitated by adding $100 \mathrm{~mL}$ acetone to the reaction solution, followed by centrifugation at $8,000 \mathrm{rpm}$ for $10 \mathrm{~min}$. The products were then washed twice by DI water through centrifugation $(14,000 \mathrm{rpm}, 10 \mathrm{~min})$. Finally, the products were re-dispersed in DI water for further use.

Ni-Pt ${ }_{2}$ NPs (sample in Figure S5) and Ni-Pt 0.5 NPs (sample in Figure S6) were synthesized using the same procedures above, except that the amounts of Pt and Ni precursors were varied: $10 \mathrm{mg}$ $(0.025 \mathrm{mmol}) \mathrm{Pt}(\mathrm{acac})_{2}$ and $3.5 \mathrm{mg}(0.013 \mathrm{mmol}) \mathrm{Ni}(\mathrm{ac})_{2} \cdot 4 \mathrm{H}_{2} \mathrm{O}$ for Ni-Pt $\mathrm{NPs}_{2}$; and $10 \mathrm{mg}(0.025$ mmol) $\mathrm{Pt}(\mathrm{acac})_{2}$ and $14 \mathrm{mg}(0.05 \mathrm{mmol}) \mathrm{Ni}(\mathrm{ac})_{2} \cdot 4 \mathrm{H}_{2} \mathrm{O}$ for Ni-Pto. $\mathrm{NPs}$.

Evaluation of Peroxidase-like Activity. Peroxidase-like activities of the NPs were evaluated by the steady-state kinetic assays, according to the procedures published in our previous paper. ${ }^{\mathrm{S} 1}$ Briefly, all the assays were conducted in $1.0 \mathrm{~mL}$ cuvettes (path length, $l=1.0 \mathrm{~cm}$ ) and $0.2 \mathrm{M}$ $\mathrm{NaOAc} / \mathrm{HOAc}$ buffer, $\mathrm{pH}$ 4.0. In a typical assay, NPs (particle concentrations are listed in Table S1) were first mixed with $0.8 \mathrm{mM} \mathrm{TMB}$ and $2.0 \mathrm{M} \mathrm{H}_{2} \mathrm{O}_{2}$ in the buffer solution and the absorbance of the reaction solution at $\lambda_{\max }=653 \mathrm{~nm}$ was immediately detected by the UV-vis spectrophotometer with the interval of 2 seconds for 1 minute. Then the "Absorbance versus Time" curve was obtained, which can be used to derive the initial reaction velocity $(v)$ through the equation: $v=$ Slopeinitial $/(\varepsilon \mathrm{TMB}-653 \mathrm{~nm} \times l)$. Herein, Slopeinitial is the first derivation from the initial point on the measured curve, $\varepsilon_{\text {TMB }}-653 \mathrm{~nm}$ is the molar extinction coefficient of oxTMB at $653 \mathrm{~nm}$ $\left(3.9 \times 10^{4} \mathrm{M}^{-1} \cdot \mathrm{cm}^{-1}\right)$ and $l$ is the path length $(1.0 \mathrm{~cm})$. Then the plot of initial reaction velocity $(v)$ against TMB concentration (Figure 2B) can be obtained and fitted by the nonlinear regression of the Michaelis-Menten equation $v=V_{\max } \times[\mathrm{S}] /\left(K_{\mathrm{m}}+[\mathrm{S}]\right)$, where $V_{\max }$ is the maximal reaction 
velocity, [S] is the concentration of TMB, and $K_{\mathrm{m}}$ is the Michaelis constant. The values of $K_{\mathrm{m}}$ and $V_{\max }$ can be obtained from the double reciprocal plots (Figure S9). The catalytic efficiency in terms of $K_{\text {cat }}$ can be calculated from equation: $K_{\text {cat }}=V_{\max } /[\mathrm{E}]$, where [E] is the particle concentration of catalysts. The area-specific catalytic efficiency in terms of $K_{\text {cat-specific }}$ can be derived by normalizing $K_{\text {cat }}$ against the surface area of a single NP.

Preparation of the Ni-Pt and Pt NP-Goat Anti-Mouse IgG Conjugates. The NP-goat antimouse IgG conjugates were prepared according to our previously published procedures with slight modifications. ${ }^{\mathrm{S1}}$ First, the Ni-Pt or Pt NP surfaces were functionalized with $\mathrm{HS}_{-\mathrm{PEG}} 3400-\mathrm{COOH}$. Briefly, $300 \mu \mathrm{L}$ HS-PEG $3400-\mathrm{COOH}$ aqueous solution $(0.5 \mathrm{mM})$ was mixed with $300 \mu \mathrm{L}$ aqueous suspension of Ni-Pt or Pt NPs $\left(8.5 \times 10^{-8} \mathrm{M}\right.$, as determined by ICP-AES) under magnetic stirring for $3 \mathrm{~h}$. Afterwards, the unbound $\mathrm{HS}-\mathrm{PEG}_{3400-\mathrm{COOH}}$ was removed by centrifuging at $14,000 \mathrm{rpm}$ for $10 \mathrm{~min}$. The precipitates (i.e., NP-S-PEG3400-COOH) were washed twice with DI water and redispersed in $300 \mu \mathrm{L}$ DI water. Second, the NP-S-PEG $3400-\mathrm{COOH}$ was conjugated with goat antimouse IgG through EDC/NHS crosslinking. ${ }^{\mathrm{S} 2}$ Specifically, $50 \mu \mathrm{L}$ of as prepared NP-S-PEG3400$\mathrm{COOH}$ solution was added to $450 \mu \mathrm{L}$ DI water. Then $5 \mu \mathrm{L}$ EDC $(25 \mathrm{mM})$ and $5 \mu \mathrm{L}$ NHS $(50 \mathrm{mM})$ aqueous solutions were added under magnetic stirring. After $30 \mathrm{~min}$, the particles were collected by centrifuging at 14,000 rpm for 10 min, washed twice with DI water and re-dispersed in $50 \mu \mathrm{L}$ $10 \mathrm{mM}$ phosphate-buffered saline (PBS, $\mathrm{pH}$ 7.4) buffer. Subsequently, $50 \mu \mathrm{L}$ goat anti-mouse $\mathrm{IgG}$ $(2.5 \mathrm{mg} / \mathrm{mL}$, in PBS) was added to this particle suspension and mixed using a shaker. After incubation at room temperature for $1 \mathrm{~h}$, the reaction solution was put in a refrigerator at $4{ }^{\circ} \mathrm{C}$ overnight. Afterwards, $100 \mu \mathrm{L}$ blocking solution (5\% BSA in PBS) was added. After $2 \mathrm{~h}$, the final products (i.e., NP-goat anti-mouse IgG conjugates) were collected by centrifugation, washed twice with PBS, and re-dispersed in $100 \mu \mathrm{L}$ PBS containing $1 \% \mathrm{BSA}$ and $0.02 \% \mathrm{NaN}_{3}$ for future use.

ELISA of CEA. 96-well microtiter plates were coated with rabbit anti-CEA pAb $(5 \mu \mathrm{g} / \mathrm{mL}$ in $\mathrm{Na}_{2} \mathrm{CO}_{3} / \mathrm{NaHCO}_{3}$ buffer $\mathrm{pH} 9.6,100 \mu \mathrm{L}$ for each well) at $4{ }^{\circ} \mathrm{C}$ overnight. The plates were then washed three times with washing buffer (10 mM PBS pH 7.4 containing $0.05 \%$ Tween 20, PBST). Afterwards, the plates were blocked by blocking buffer (2\% BSA and $0.02 \% \mathrm{NaN}_{3}$ in PBST, 200 $\mu \mathrm{L}$ for each well). After mild shaking at room temperature for $1 \mathrm{~h}$, the plates were washed three times with washing buffer. $100 \mu \mathrm{L}$ CEA standards with specific concentrations in dilution buffer 
( $1 \% \mathrm{BSA}$ and $0.02 \% \mathrm{NaN}_{3}$ in PBST) were added to the wells, followed by mild shaking at room temperature for $2 \mathrm{~h}$. After washing three times with washing buffer, to each well $100 \mu \mathrm{L}$ mouse anti-CEA mAb ( $2 \mu \mathrm{g} / \mathrm{mL}$, in dilution buffer) was added, followed by mild shaking at room temperature for $1 \mathrm{~h}$ and three times washing with washing buffer.

For the Ni-Pt- and Pt-ELISAs, $100 \mu \mathrm{L}$ corresponding NP-goat anti-mouse IgG conjugates (1:5000, in dilution buffer) was added to each well of the plate. The plate was incubated at room temperature for $1 \mathrm{~h}$. After washing four times with washing buffer, $100 \mu \mathrm{L}$ freshly prepared substrate solution ( $0.8 \mathrm{mM} \mathrm{TMB}$ and $2.0 \mathrm{M} \mathrm{H}_{2} \mathrm{O}_{2}$ in $0.2 \mathrm{M} \mathrm{HOAc} / \mathrm{NaOAc}$ buffer, $\mathrm{pH} 4.0$ ) was added to each well. After $20 \mathrm{~min}, 50 \mu \mathrm{L}$ of $2.0 \mathrm{M} \mathrm{H}_{2} \mathrm{SO}_{4}$ as stopping solution was added to each well. Then a microplate reader was used to measure the value of absorbance at $450 \mathrm{~nm}$ for each well.

For the HRP-ELISA, the procedure was the same as the Ni-Pt- and Pt-ELISAs above, except for the substitutions of NP-goat anti-mouse IgG conjugates with $100 \mu \mathrm{L}$ HRP-goat anti-mouse IgG conjugates ( $1 \mu \mathrm{g} / \mathrm{mL}$, in dilution buffer) and the change of the substrate solution to $0.8 \mathrm{mM}$ TMB and $5 \mathrm{mM} \mathrm{H}_{2} \mathrm{O}_{2}$ in citric acid/ $\mathrm{Na}_{2} \mathrm{HPO}_{4}$ buffer, $\mathrm{pH} 5.0$.

DFT calculations. Density functional theory (DFT) calculations were performed with the Vienna $\mathrm{ab}$ initio Simulation Package (VASP). ${ }^{\mathrm{S} 3 \mathrm{S4}}$ The Perdew-Burke-Ernzerhof $(\mathrm{PBE})^{\mathrm{S} 5}$ functional form of generalized-gradient approximation (GGA) for electron exchange and correlation energies were used. All calculations were performed with spin polarization. The projector-augmented wave method was used to describe the electron-core interaction ${ }^{\mathrm{S} 3, \mathrm{~S} 6}$ with a kinetic energy cutoff of 450 $\mathrm{eV}$ for the calculations. A k-point mesh of $3 \times 3 \times 1$ for sampling using the Monkhorst-Pack scheme was used. ${ }^{\mathrm{S} 7}$ The slabs were created by first optimizing the bulk lattice for a given subsurface composition and cleaving along (111) or equivalent facet to create the surface. The Pt overlayer was then created with the same lattice spacing as the subsurface layers. A vacuum layer of $15 \AA$ was created for the surface slabs; the slab contains a total of four layers, with the bottom two layers of the surface slab fixed in the calculations. The absorption energy $\left(E_{\text {ads }}\right)$ is calculated with the equation $E_{\text {ads }}=E_{\text {slab+adsorbate }}-\left(E_{\text {slab }}+E_{\text {adsorbate }}\right)$ where $E_{\text {slab+adsorbate }}$ is the energy of the surface slab with the adsorbate. The energies of $E_{\text {adsorbate }}$ were computed by placing the adsorbate in a cubic cell with a $15 \AA$ wide vacuum in each direction. 


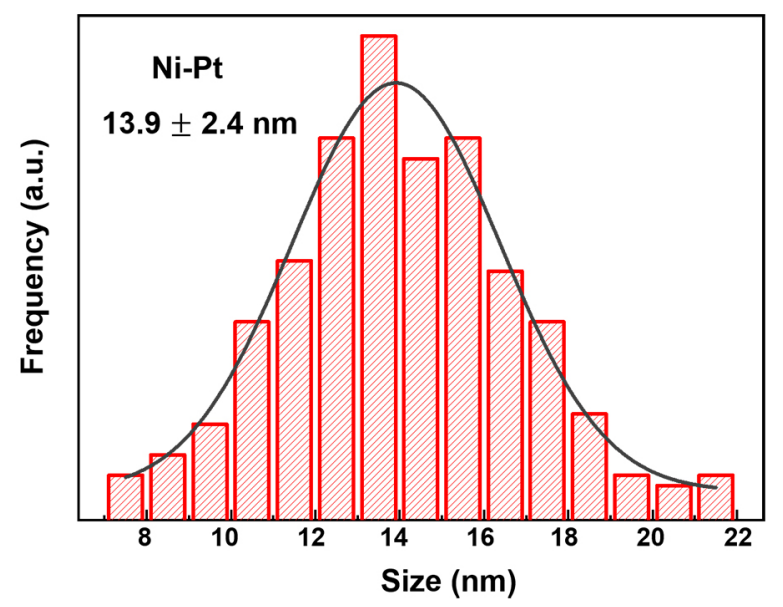

Figure S1. Size distribution of the Ni-Pt NPs shown in Figure 1. 


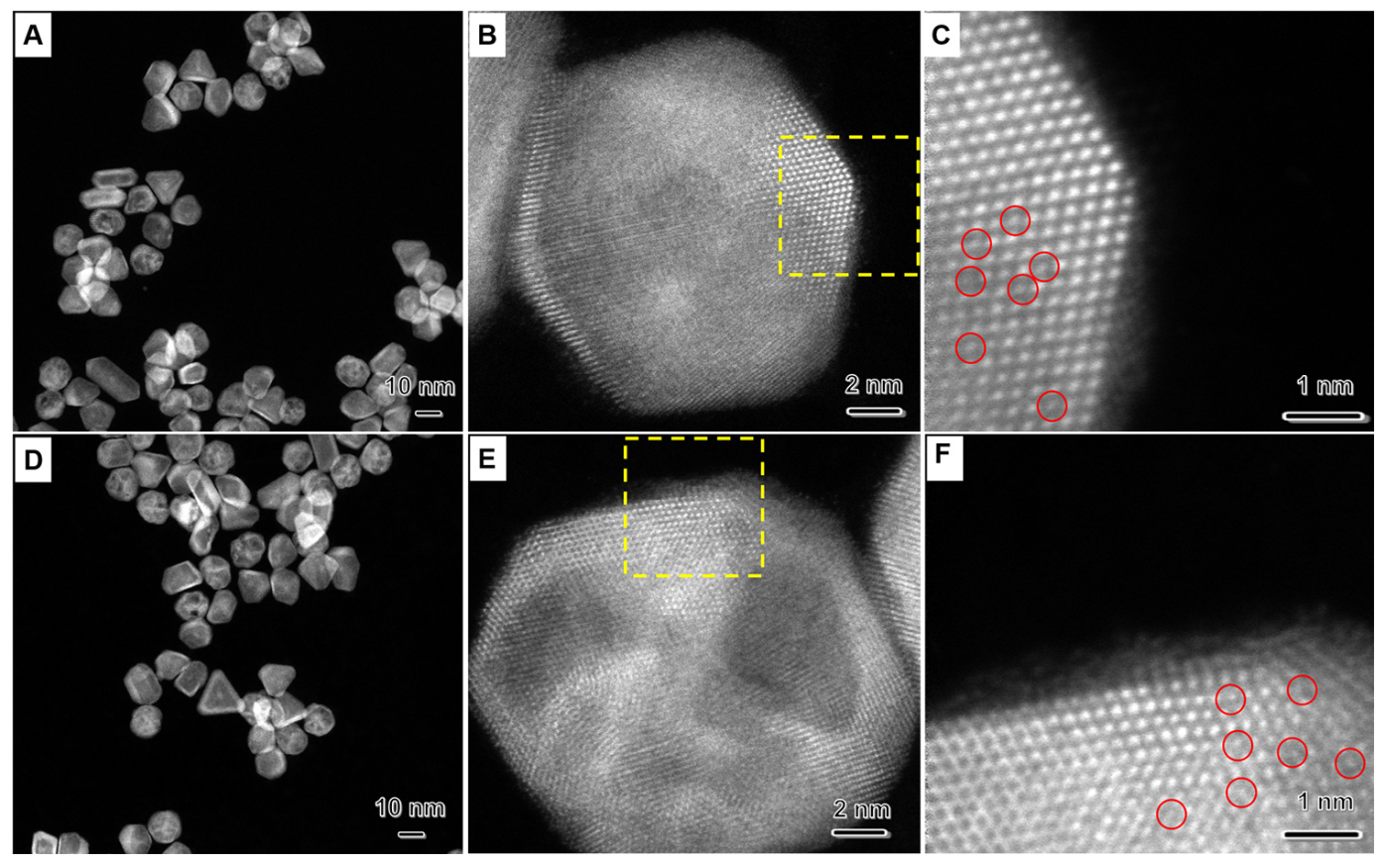

Figure S2. Representative HAADF-STEM images taken from two additional Ni-Pt NP samples that were obtained from two different batches of synthesis: (A-C) batch \#1 and (D-F) batch \#2. (A, D) low-magnification images; $(\mathrm{B}, \mathrm{E})$ images of individual particles; (C, F) magnified images of the areas marked by dashed squares in (B) and (E), respectively. Red circles in (C, F) highlight regions containing $\mathrm{Ni}$ atoms. 


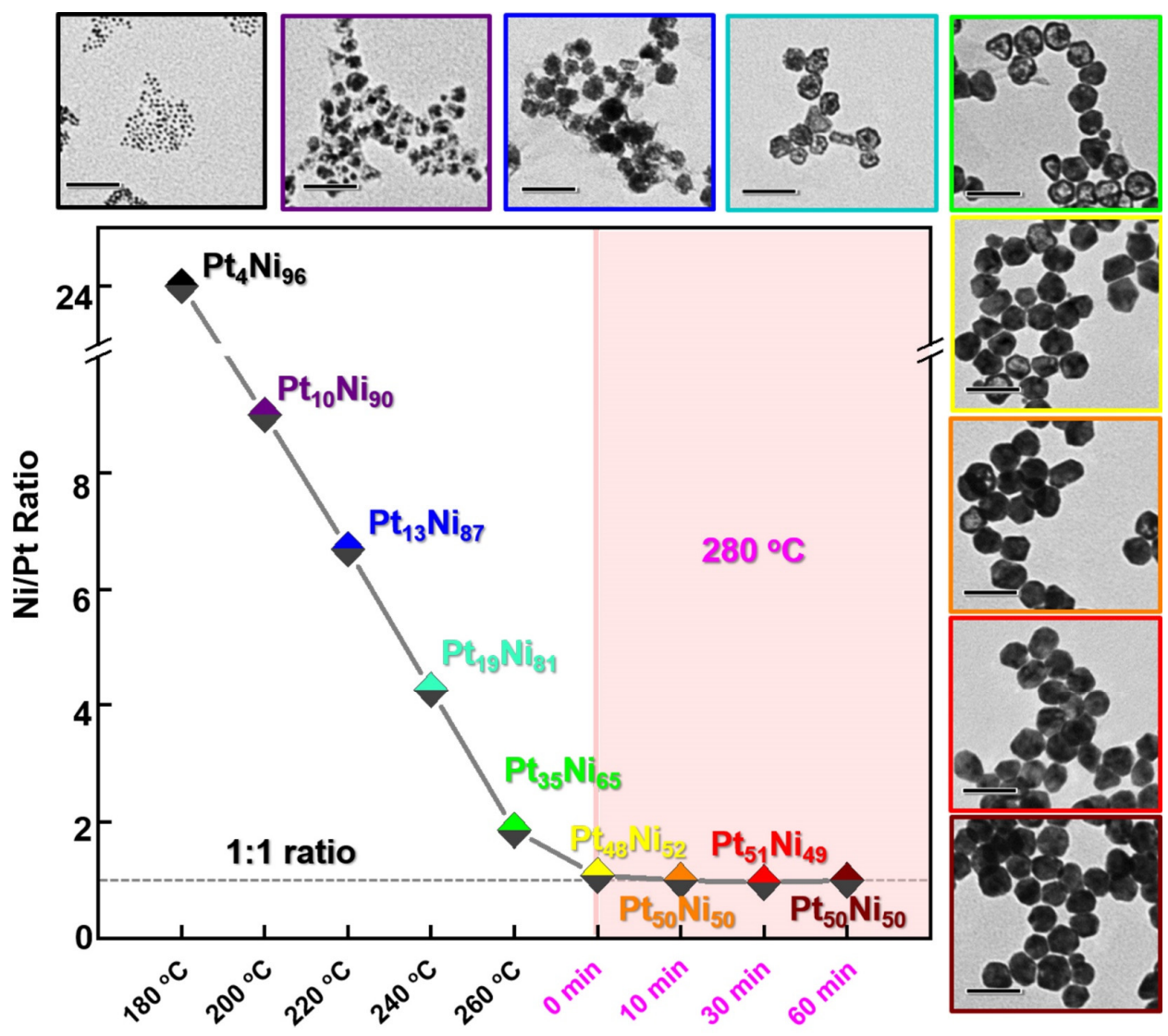

Figure S3. Analysis of products obtained from the standard synthesis of Ni-Pt NPs at different stages. The Ni/Pt ratio was determined by ICP-AES. The scale bars in TEM images are $20 \mathrm{~nm}$. TEM images of colored frames correspond to the data points (i.e., diamond symbols in the plot) with the same color. 

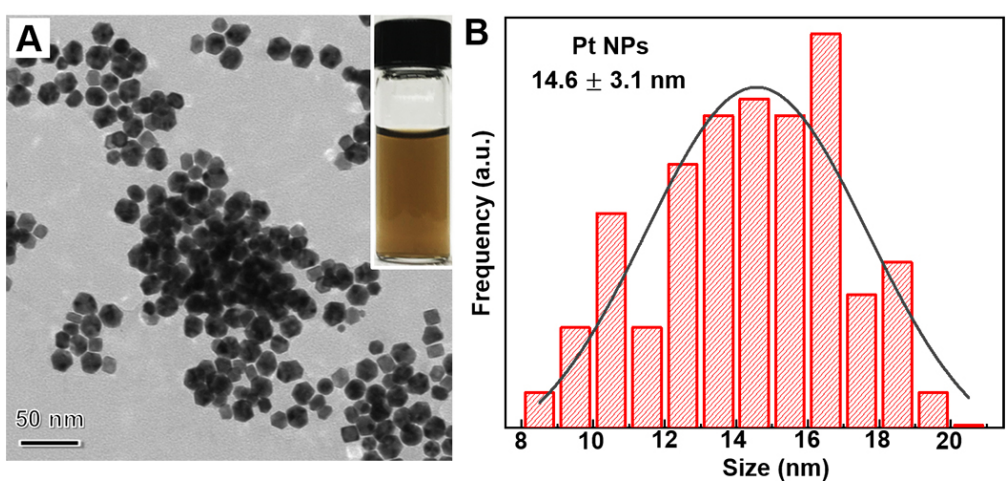

Figure S4. (A) TEM image Pt NPs. Inset shows a photograph of an aqueous suspension of the Pt NPs. (B) Size distribution of the Pt NPs shown in (A). 

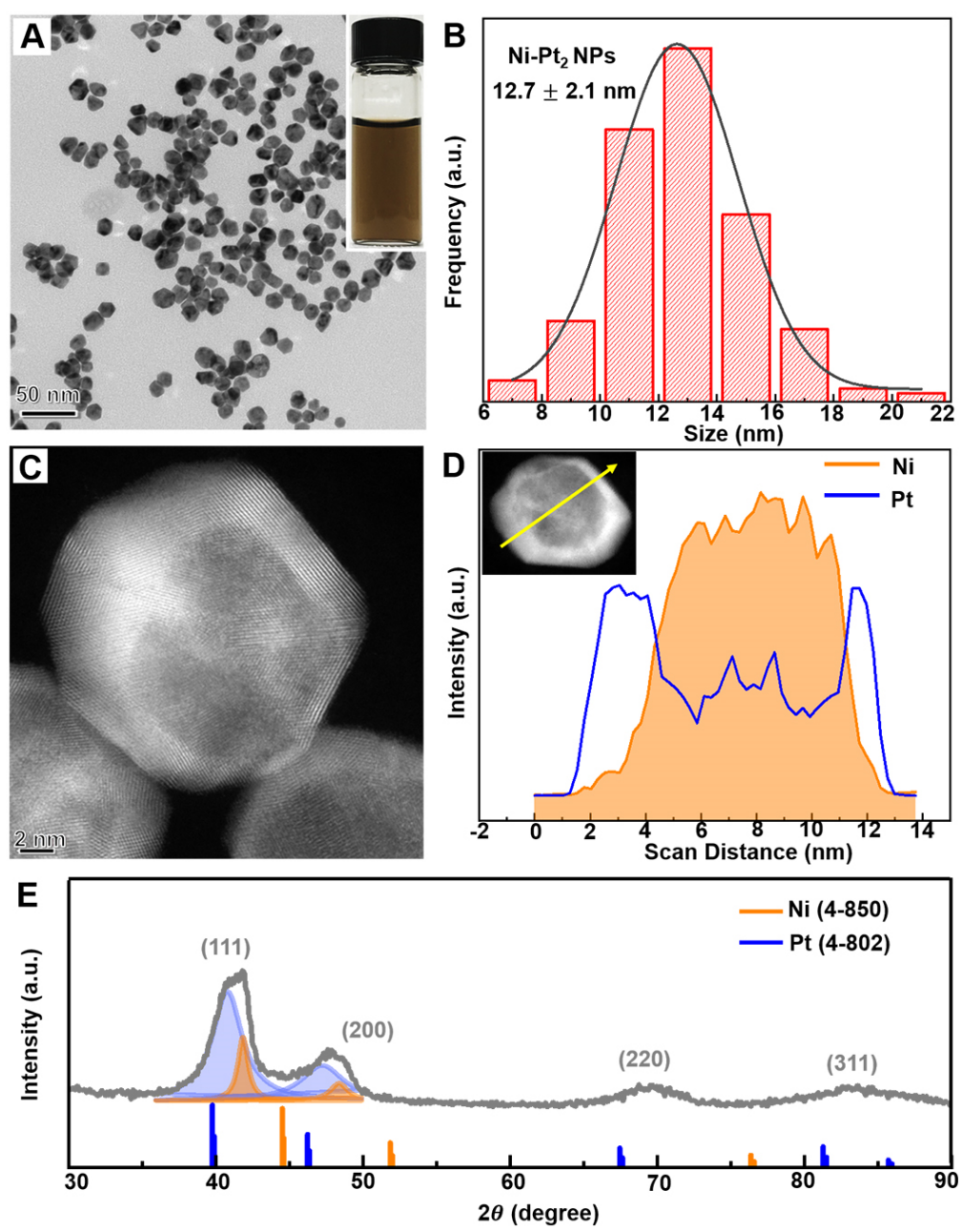

Figure S5. Structural and compositional analyses of Ni-Pt 2 NPs. (A) TEM image, along with a photograph (inset) of the Ni-Pt 2 NPs dispersed in deionized water; (B) Size distribution of the NPs; (C) STEM image; (D) EDS line-scan recorded from an individual NP (inset) along the direction indicated by the yellow arrow; (E) XRD pattern. 

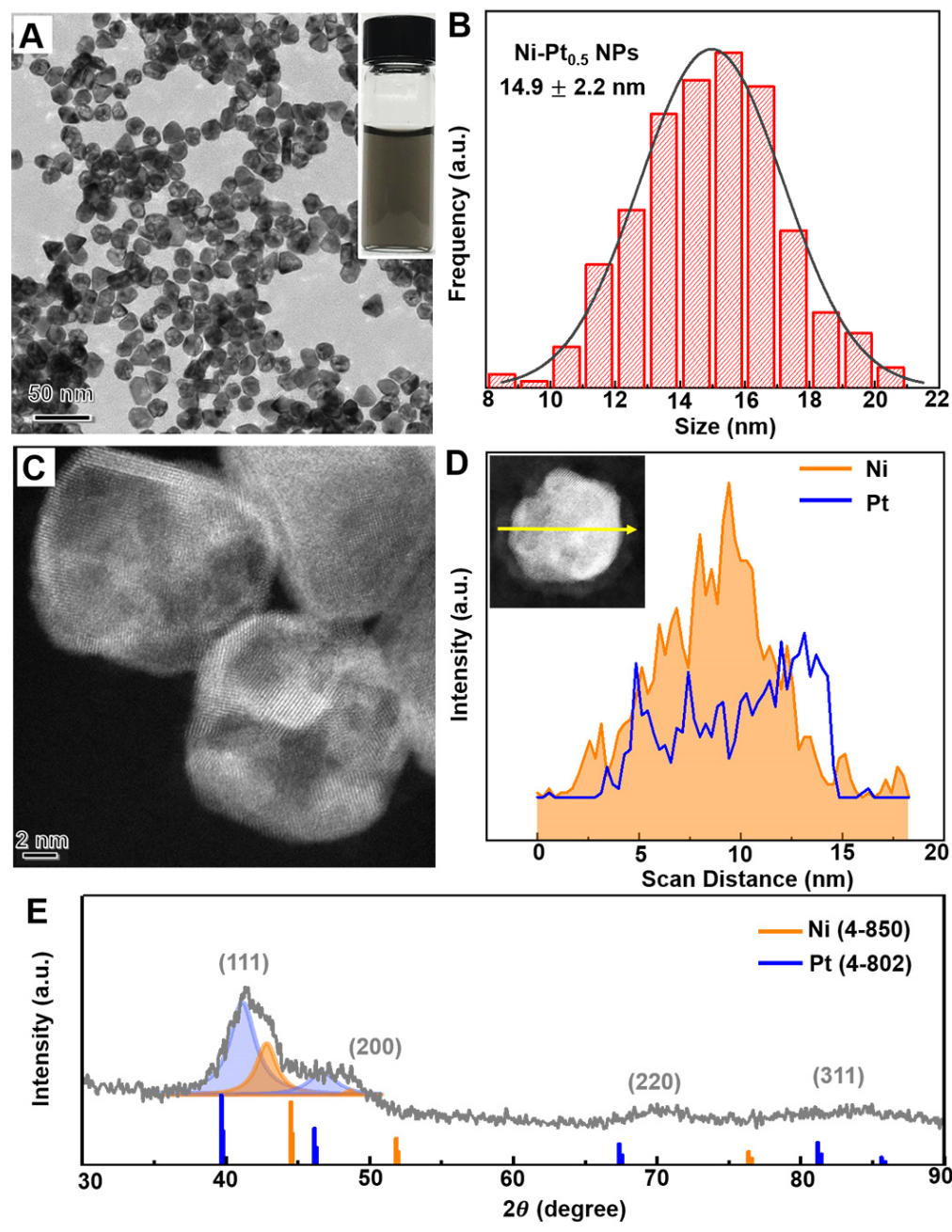

Figure S6. Structural and compositional analyses of Ni-Pt 0.5 Ps. (A) TEM image, along with a photograph (inset) of the Ni-Pt 0.5 NPs dispersed in deionized water; (B) Size distribution of the NPs; (C) STEM image; (D) EDS line-scan recorded from an individual NP (inset) along the direction indicated by the yellow arrow; (E) XRD pattern. 


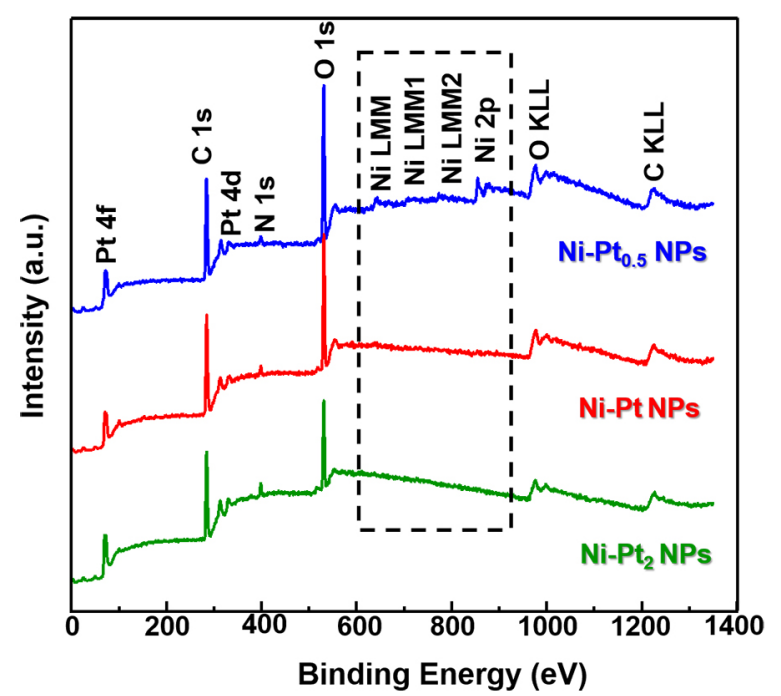

Figure S7. XPS survey spectra recorded from three types of NPs with different Ni/Pt ratios as labeled in the spectra. 

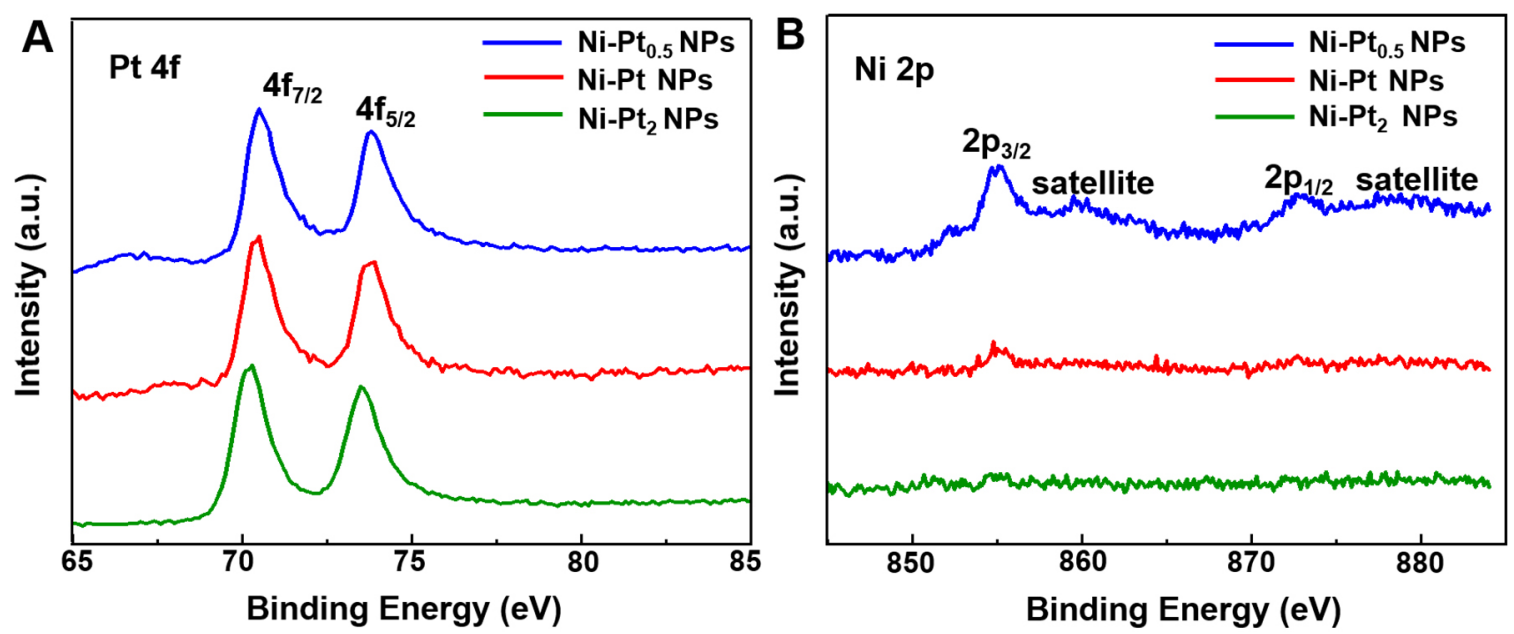

Figure S8. XPS spectra of (A) Pt $4 \mathrm{f}$ region and (B) Ni $2 p$ region that were recorded from NPs with different $\mathrm{Ni} / \mathrm{Pt}$ ratios. 

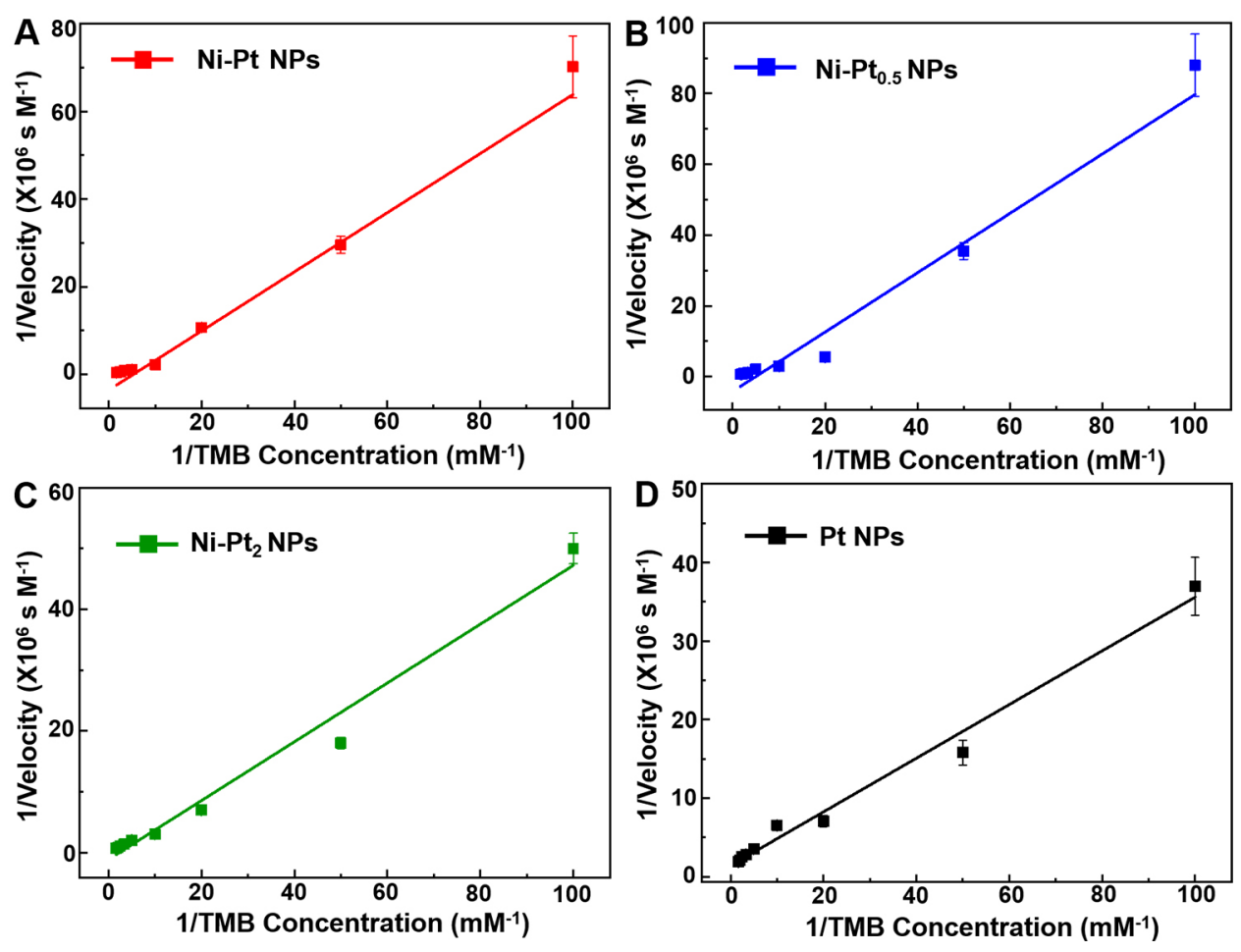

Figure S9. Double-reciprocal plots for: (A) Ni-Pt NPs; (B) Ni-Pt 0.5 NPs; (C) Ni-Pt 2 NPs; and (D) Pt NPs that were generated from Figure 2B. Error bars indicate the standard deviations of three independent measurements. 

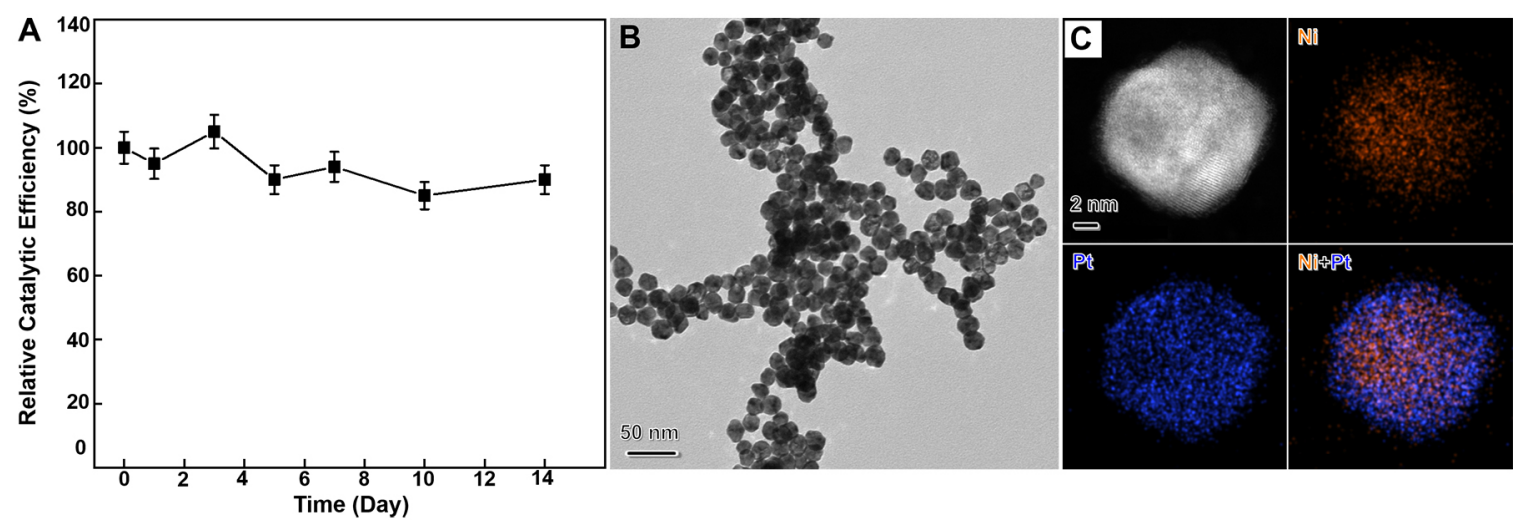

Figure S10. (A) The change of catalytic efficiency of Ni-Pt NPs as a function of storage time. After production from a standard synthesis, the Ni-Pt NPs were stored in deionized water at room temperature and then their relative catalytic efficiencies at different storage times were measured (i.e., absorbance at $653 \mathrm{~nm}$ of catalytic reaction solutions at $t=1$ minute, under the conditions of the steady-state kinetic assays), where the catalytic efficiency of day 0 (freshly prepared sample) was set to $100 \%$. Error bars in the plot indicate standard deviations of three independent measurements. (B, C): Characterizations of the Ni-Pt NPs after they had been stored for 14 days. (B) TEM image and (C) EDS mapping image. 


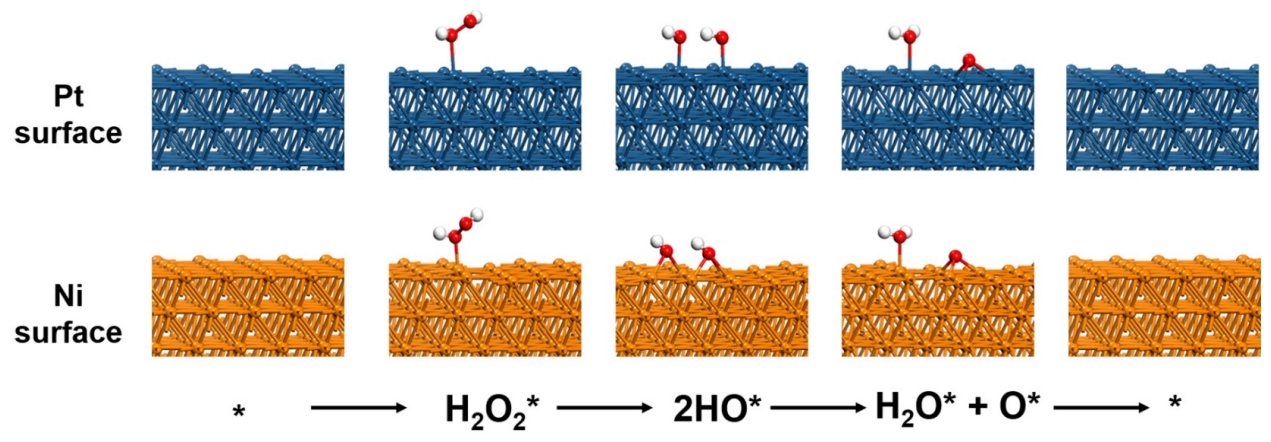

Figure S11. The optimized intermediate adsorption configurations on $\mathrm{Pt}$ and $\mathrm{Ni}$ surfaces, respectively. 


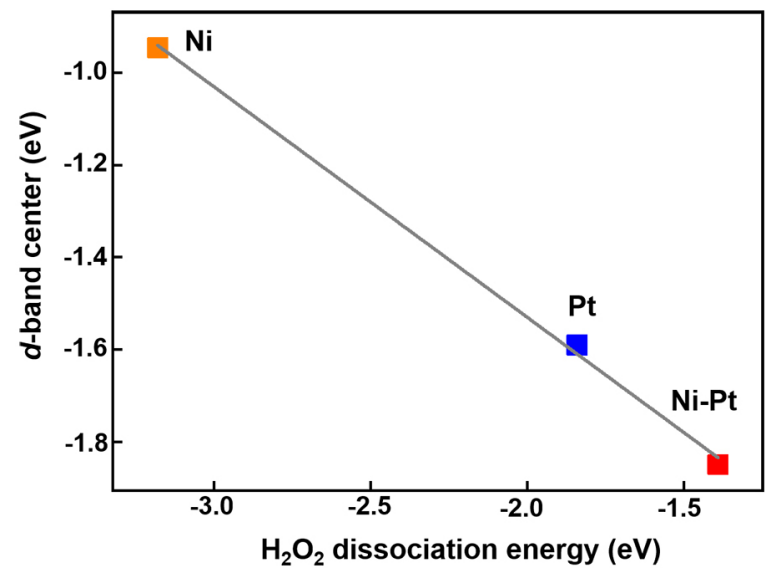

Figure S12. $d$-band center versus $\mathrm{H}_{2} \mathrm{O}_{2}$ dissociation energy for Ni, Pt and Ni-Pt surfaces. 
Table S1. Comparison of the kinetic parameters of different catalysts toward the oxidation of TMB by $\mathrm{H}_{2} \mathrm{O}_{2}$. $[E]$ is the particle concentration of catalysts, $K_{\mathrm{m}}$ is the Michaelis constant, $V_{\max }$ is the maximal reaction velocity, $K_{\text {cat }}$ is the catalytic constant that equals $V_{\max } /[E]$, and $K_{\text {cat-specific }}$ is the specific catalytic efficiency that is derived by normalizing $K_{\text {cat }}$ against the surface area of a single catalyst.

\begin{tabular}{|c|c|c|c|c|c|c|}
\hline Catalyst & $\begin{array}{l}{[E]} \\
(\mathbf{M})\end{array}$ & Substrate & $\begin{array}{l}K_{\mathbf{m}} \\
(\mathbf{M})\end{array}$ & $\begin{array}{c}V_{\max } \\
\left(M \mathbf{s}^{-1}\right)\end{array}$ & $\begin{array}{l}K_{\text {cat }} \\
\left(\mathbf{s}^{-1}\right)\end{array}$ & $\begin{array}{r}K_{\text {cat-specific }} \\
\left(\mathrm{s}^{-1} \mathrm{~nm}^{-2}\right)\end{array}$ \\
\hline Pt NPs & $8.2 \times 10^{-13}$ & $\mathrm{TMB}$ & $4.8 \times 10^{-4}$ & $7.9 \times 10^{-7}$ & $9.7 \times 10^{5}$ & $1.5 \times 10^{3}$ \\
\hline $\mathrm{Ni}-\mathrm{Pt}_{2}$ NPs & $7.7 \times 10^{-13}$ & $\mathrm{TMB}$ & $9.0 \times 10^{-3}$ & $6.1 \times 10^{-6}$ & $8.0 \times 10^{6}$ & $1.6 \times 10^{4}$ \\
\hline $\mathrm{Ni}-\mathrm{Pt}$ NPs & $5.8 \times 10^{-13}$ & $\mathrm{TMB}$ & $3.5 \times 10^{-2}$ & $2.6 \times 10^{-5}$ & $4.5 \times 10^{7}$ & $7.4 \times 10^{4}$ \\
\hline $\mathrm{Ni}-\mathrm{Pt}_{0.5} \mathrm{NPs}$ & $8.5 \times 10^{-13}$ & $\mathrm{TMB}$ & $1.3 \times 10^{-2}$ & $1.5 \times 10^{-5}$ & $1.7 \times 10^{7}$ & $2.5 \times 10^{4}$ \\
\hline HRP* & $2.5 \times 10^{-11}$ & TMB & $4.3 \times 10^{-4}$ & $1.0 \times 10^{-7}$ & $4.3 \times 10^{3}$ & - \\
\hline
\end{tabular}

*Data retrieved from Ref S8. 
Table S2. Comparison of the catalytic efficiencies (in terms of both $K_{\text {cat }}$ and $K_{\text {cat-specific }}$ ) of various peroxidase mimics.

\begin{tabular}{|c|c|c|c|c|}
\hline Peroxidase mimic & $\begin{array}{l}\text { Size } \\
(\mathbf{n m})\end{array}$ & $\begin{array}{l}K_{\text {cat }} \\
\left(\mathbf{s}^{-1}\right)\end{array}$ & $\begin{array}{r}K_{\text {cat-specific }}{ }^{*} \\
\left(\mathrm{~s}^{-1} \mathrm{~nm}^{-2}\right)\end{array}$ & References \\
\hline $\mathrm{Fe}_{3} \mathrm{O}_{4}$ particles & 300 (diameter) & $3.0 \times 10^{4}$ & $1.1 \times 10^{-1}$ & $\mathrm{~S} 8$ \\
\hline $\mathrm{Fe}_{2} \mathrm{O}_{3}$ particles & 10 (diameter) & $3.4 \times 10^{3}$ & $1.1 \times 10^{1}$ & S9 \\
\hline FePt particles & 1.87 (diameter) & $7.6 \times 10^{3}$ & $6.8 \times 10^{2}$ & $\mathrm{~S} 10$ \\
\hline $\mathrm{Au} @ \mathrm{Pt}$ rods & $30 \times 70($ width $\times$ length $)$ & $1.4 \times 10^{4}$ & $2.1 \times 10^{0}$ & $\mathrm{~S} 11$ \\
\hline $\mathrm{V}_{2} \mathrm{O}_{5}$ wires & $100 \times 500$ (width $\times$ length $)$ & $2.5 \times 10^{3}$ & $1.4 \times 10^{-2}$ & $\mathrm{~S} 12$ \\
\hline $\mathrm{Au} @ \mathrm{Pt}$ rods & $20 \times 70$ (width $\times$ length $)$ & $5.7 \times 10^{3}$ & $1.1 \times 10^{1}$ & $\mathrm{~S} 13$ \\
\hline $\mathrm{Co}_{3} \mathrm{O}_{4}$ cubes & 20 (edge length) & $1.8 \times 10^{2}$ & $7.2 \times 10^{-2}$ & $\mathrm{~S} 14$ \\
\hline $\begin{array}{c}\mathrm{PdPt}-\mathrm{Fe}_{3} \mathrm{O}_{4} \\
\text { dumbbell }\end{array}$ & 12 (diameter) & $2.4 \times 10^{1}$ & $5.3 \times 10^{-3}$ & S15 \\
\hline Au@Pd particles & 20 (diameter) & $2.1 \times 10^{4}$ & $1.7 \times 10^{1}$ & $\mathrm{~S} 16$ \\
\hline $\mathrm{Cu}(\mathrm{OH})_{2}$ supercages & 200 (edge length) & $3.8 \times 10^{4}$ & - & $\mathrm{S} 17$ \\
\hline Pd cubes & 18 (edge length) & $6.9 \times 10^{4}$ & $3.5 \times 10^{1}$ & $\mathrm{~S} 1$ \\
\hline Pd-Ir cubes & 19.2 (edge length) & $1.9 \times 10^{6}$ & $8.6 \times 10^{2}$ & $\mathrm{~S} 1$ \\
\hline Ir particles & 1.5 (diameter) & $5.6 \times 10^{1}$ & $7.8 \times 10^{0}$ & $\mathrm{~S} 18$ \\
\hline $\begin{array}{c}\mathrm{Pd} @ \mathrm{Pt} 2 \mathrm{D} \\
\text { hexagonal nanosheet }\end{array}$ & 40 (edge length) & $3.1 \times 10^{4}$ & $3.7 \times 10^{1}$ & S19 \\
\hline $\mathrm{Ru}$ frames & 10 (diameter) & $1.3 \times 10^{4}$ & $4.1 \times 10^{2}$ & $\mathrm{~S} 20$ \\
\hline $\begin{array}{l}\text { high-index facet Pt } \\
\text { concave cubes }\end{array}$ & 44 (edge length) & $6.0 \times 10^{6}$ & $5.2 \times 10^{2}$ & $\mathrm{~S} 21$ \\
\hline Pt cubes & 7.35 (edge length) & $8.2 \times 10^{5}$ & $2.5 \times 10^{3}$ & $\mathrm{~S} 22$ \\
\hline Au@Pt particles & 40.2 (diameter) & $1.0 \times 10^{6}$ & $2.0 \times 10^{2}$ & $\mathrm{~S} 23$ \\
\hline Porous Pd-Ru cubes & 20 (edge length) & $4.8 \times 10^{5}$ & $2.0 \times 10^{2}$ & $\mathrm{~S} 24$ \\
\hline $\begin{array}{l}\text { Pt hollow } \\
\text { nanodendrites }\end{array}$ & 20 (length) & $1.7 \times 10^{-2}$ & - & $\mathrm{S} 25$ \\
\hline $\mathrm{LaNiO}_{3-\delta}$ perovskite & aggregate & $7.8 \times 10^{3}$ & $4.6 \times 10^{2}$ & $\mathrm{~S} 26$ \\
\hline
\end{tabular}




\begin{tabular}{ccccc} 
Si-CoO rods & $50 \times 500$ (width $\times$ length) & $1.8 \times 10^{2}$ & $2.2 \times 10^{-3}$ & S27 \\
NB-rGO sheets & 200 (diameter) & $6.6 \times 10^{4}$ & $2.1 \times 10^{0}$ & S28 \\
Pd-Pt cubes & 42.3 (edge length) & $9.4 \times 10^{6}$ & $8.8 \times 10^{2}$ & S29 \\
Pt particles & 14.6 (diameter) & $9.7 \times 10^{5}$ & $1.5 \times 10^{3}$ & This work \\
$\begin{array}{c}\text { Core-shell } \\
\text { Ni-Pt particles }\end{array}$ & 12.7 (diameter) & $8.0 \times 10^{6}$ & $1.6 \times 10^{4}$ & This work \\
Core-shell & 13.9 (diameter) & $4.5 \times 10^{7}$ & $7.4 \times 10^{4}$ & This work \\
Ni-Pt particles & 14.9 (diameter) & $1.7 \times 10^{7}$ & $2.5 \times 10^{4}$ & This work \\
Core-shell & & & \\
Ni-Pt 0.5 particles & & & & \\
\hline
\end{tabular}

${ }^{*} K_{\text {cat-specific was calculated by dividing } K_{\text {cat }} \text { by the surface area of a single peroxidase mimic, which }}$ was estimated on the basis of particle sizes and shapes reported in the literature. 


\section{References}

(S1) Xia, X.; Zhang, J.; Lu, N.; Kim, M. J.; Ghale, K.; Xu, Y.; McKenzie, E.; Liu, J.; Ye, H. PdIr Core-Shell Nanocubes: A Type of Highly Efficient and Versatile Peroxidase Mimic. ACS Nano 2015, 9, 9994-10004.

(S2) Vashist, S. K. Comparison of 1-Ethyl-3-(3-Dimethylaminopropyl) Carbodiimide Based Strategies to Crosslink Antibodies on Amine-Functionalized Platforms for Immunodiagnostic Applications. Diagnostics 2012, 2, 23-33.

(S3) Kresse,G.; Furthmuller, J. Efficiency of Ab-initio Total Energy Calculations for Metals and Semiconductors Using A Plane-wave Basis Set. Comput. Mater. Sci. 1996, 6, 15-50.

(S4) Kresse, G.; Furthmuller, J. Efficient Iterative Schemes for Ab-initio Total-energy Calculations Using A Plane-wave Basis Set. J. Phys. Rev. B 1996, 54, 11169-11186.

(S5) Perdew, J. P.; Burke, K.; Ernzerhof, M. Generalized Gradient Approximation Made Simple. Phys. Rev. Lett. 1996, 77, 3865-3868.

(S6) Blöchl, P. E. Projector Augmented-wave Method. Phys. Rev. B 1994, 50, 17953-17979.

(S7) Monkhorst, H. J.; Pack, J. D. Special Points for Brillouin-zone Integrations. Phys. Rev. B 1976, 13, 5188-5192.

(S8) Gao, L.; Zhuang, J.; Nie, L.; Zhang, J.; Zhang, Y.; Gu, N.; Wang, T.; Feng, J.; Yang, D.; Perrett, S.; Yan, X. Intrinsic Peroxidase-like Ac-tivity of Ferromagnetic Nanoparticles. Nat. Nanotechnol. 2007, 2, 577-583.

(S9) Zhang, X.; Gong, S.; Zhang, Y.; Yang, T.; Wang, C.; Gu, N. Prussian Blue Modified Iron Oxide Magnetic Nanoparticles and Their High Peroxidase-like Activity. J. Mater. Chem. 2010, 20, 5110-5116.

(S10) Fan, J.; Yin, J. J.; Ning, B.; Wu, X.; Hu, Y.; Ferrari, M.; Anderson, G. J.; Wei, J.; Zhao, Y.; Nie, G. Direct Evidence for Catalase and Peroxidase Activities of Ferritin-Platinum Nanoparticles. Biomaterials 2011, 32, 1611-1618.

(S11) He, W.; Liu, Y.; Yuan, J.; Yin, J. J.; Wu, X.; Hu, X.; Zhang, K.; Liu, J.; Chen, C.; Ji, Y.; Guo, Y.Au@Pt Nanostructures as Oxidase and Peroxidase Mimetics for Use in Immunoassays. Biomaterials 2011, 32, 1139-1147.

(S12) André, R.; Natálio, F.; Humanes, M.; Leppin, J.; Heinze, K.; Wever, R.; Schröder, H. C.; Müller, W. E. G.; Tremel, W. $\mathrm{V}_{2} \mathrm{O}_{5}$ Nanowires with an Intrinsic Peroxidase-Like Activity. Adv. Funct. Mater. 2011, 21, 501-509.

(S13) Liu, J.; Hu, X.; Hou, S.; Wen, T.; Liu, W.; Zhu, X.; Yin, J.; Wu, X. Au@Pt Core/Shell Nanorods with Peroxidase- and Ascorbate Oxidase-like Activities for Improved Detection of Glucose. Sens. Actuators B, Chem. 2012, 166, 708.

(S14) Mu, J.; Wang, Y.; Zhao, M.; Zhang, L. Intrinsic Peroxidase-like Activity and Catalase-like Activity of $\mathrm{Co}_{3} \mathrm{O}_{4}$ Nanoparticles. Chem. Commun. 2012, 48, 2540-2542.

(S15) Sun, X.; Guo, S.; Chung, C. S.; Zhu, W.; Sun, S. A Sensitive $\mathrm{H}_{2} \mathrm{O}_{2}$ Assay based on Dumbbell-like PtPd-Fe $\mathrm{O}_{4}$ Nanoparticles. Adv. Mater. 2013, 25, 132-136.

(S16) Gao, Z.; Hou, L.; Xu, M.; Tang, D. Enhanced Colorimetric Immunoassay Accompanying with Enzyme Cascade Amplification Strategy for Ultrasensitive Detection of LowAbundance Protein. Sci. Rep. 2014, 4, 3966. 
(S17) Cai, R.; Yang, D.; Peng, S.; Chen, X.; Huang, Y.; Liu, Y.; Hou, W.; Yang, S.; Liu, Z.; Tan, W. Single Nanoparticle to 3D Supercage: Framing for an Artificial Enzyme System. J. Am. Chem. Soc. 2015, 137, 13957-13963.

(S18) Su, H.; Liu, D. D.; Zhao, M.; Hu, W. L.; Xue, S. S.; Cao, Q.; Le, X. Y.; Ji, L. N.; Mao, Z. W. Dual-Enzyme Characteristics of Polyvinylpyrrolidone-Capped Iridium Nanoparticles and Their Cellular Protective Effect against $\mathrm{H}_{2} \mathrm{O}_{2}$-Induced Oxidative Damage. ACS Appl. Mater. Inter. 2015, 7, 8233-8242.

(S19) Wei, J.; Chen, X.; Shi, S.; Mo, S.; Zheng, N. An Investigation of the Mimetic Enzyme Activity of Two-Dimensional Pd-based Nanostructures. Nanoscale 2015, 7, 19018-19026.

(S20) Ye, H.; Mohar, J.; Wang, Q.; Catalano, M.; Kim, M. J.; Xia, X. Peroxidase-like Properties of Ruthenium Nanoframes. Sci. Bull. 2016, 61, 1739-1745.

(S21) Gao, Z.; Lv, S.; Xu, M.; Tang, D. High-index \{hk0\} Faceted Platinum Concave Nanocubes with Enhanced Peroxidase-like Activity for an Ultrasensitive Colorimetric Immunoassay of the Human Prostate-specific Antigen. Analyst 2017, 142, 911-917.

(S22) Ye, H.; Liu, Y.; Chhabra, A.; Lilla, E.; Xia, X. Polyvinylpyrrolidone (PVP)-Capped Pt Nanocubes with Superior Peroxidase-Like Activity. ChemNanoMat 2017, 3, 33-38.

(S23) Gao, Z.; Ye, H.; Tang, D.; Tao, J.; Habibi, S.; Minerick, A.; Tang, D.; Xia, X. PlatinumDecorated Gold Nanoparticles with Dual Functionalities for Ultrasensitive Colorimetric in Vitro Diagnostics. Nano Lett. 2017, 17, 5572-5579.

(S24) Wan, S.; Wang, Q.; Ye, H.; Kim, M. J.; Xia, X. Pd-Ru Bimetallic Nanocrystals with a Porous Structure and Their Enhanced Catalytic Properties. Part. Part. Syst. Charact. 2018, 1700386.

(S25) Wu, R.; Chong, Y.; Fang, G.; Jiang, X.; Pan, Y.; Chen, C.; Yin, J.; Ge, C. Synthesis of Pt Hollow Nanodendrites with Enhanced Peroxi-dase-like Activity against Bacterial Infections: Implication for Wound Healing. Adv. Funct. Mater. 2018, 28, 1801484.

(S26) Wang, X.; Gao, X.; Qin, L.; Wang, C.; Song, L.; Zhou, Y.; Zhu, G.; Cao, W.; Lin, S.; Zhou,

L.; Wang, K.; Zhang, H.; Jin, Z.; Wang, P.; Gao, X.; Wei, H. eg Occupancy as an Effective Descriptor for the Catalytic Activity of Perovskite Oxide-based Peroxidase Mimics. Nat. Commun. 2019, 10, 704.

(S27) Jin, C.; Lian, J.; Gao, Y.; Guo, K.; Wu, K.; Gao, L.; Zhang, X.; Zhang, X.; Liu, Q. Si Doped $\mathrm{CoO}$ Nanorods as Peroxidase Mimics for Colorimetric Sensing of Reduced Glutathione. ACS Sustain. Chem. Eng. 2019, 7, 13989-13998.

(S28) Kim, M. S.; Cho, S.; Joo, S. H.; Lee, J.; Kwak, S. K.; Kim, M. I.; Lee, J. N- and B-Codoped Graphene: A Strong Candidate to Replace Natural Peroxidase in Sensitive and Selective Bioassays. ACS Nano 2019, 13, 4312-4321.

(S29) Davidson, E.; Xi, Z.; Gao, Z.; Xia, X. Ultrafast and Sensitive Colorimetric Detection of Ascorbic Acid with Pd-Pt Core-Shell Nanostructure as Peroxidase Mimic. Sens. Int. 2020, 1, 100031. 